\title{
A specialist flea beetle manipulates and tolerates the activated chemical defense in its host plant
}

\section{Theresa Sporer ${ }^{1}$, Johannes Körnig ${ }^{1}$, Natalie Wielsch² ${ }^{2}$ Steffi Gebauer-Jung ${ }^{3}$, Michael Reichelt $^{4}$, Yvonne Hupfer ${ }^{2}$, Franziska Beran ${ }^{1 *}$}

${ }^{1}$ Research Group Sequestration and Detoxification in Insects, Max Planck Institute for Chemical Ecology, Jena Germany

${ }^{2}$ Research Group Mass Spectrometry/Proteomics, Max Planck Institute for Chemical Ecology, Jena Germany

${ }^{3}$ Department of Entomology, Max Planck Institute for Chemical Ecology, Jena Germany

${ }^{4}$ Department of Biochemistry, Max Planck Institute for Chemical Ecology, Jena Germany

*Correspondence:

Franziska Beran

Phone: 0049-3641-571553

fberan@ice.mpg.de

\section{Abstract}

Glucosinolates, the characteristic secondary metabolites of Brassicales, are hydrolyzed upon herbivory by myrosinases to toxic and deterrent defense metabolites. The specialist flea beetle, Phyllotreta armoraciae, sequesters glucosinolates in the body despite myrosinase activity, but it is unknown whether plant myrosinase activity influences sequestration and how beetles prevent the hydrolysis of ingested glucosinolates. In feeding experiments performed with the myrosinasedeficient Arabidopsis thaliana $\operatorname{tg} \operatorname{l} 1 \times \operatorname{tgg} 2$ ( $\operatorname{tg} g$ ) mutant and the corresponding wild type, we found that plant myrosinases reduced the glucosinolate sequestration rate by up to $50 \%$ and hydrolyzed a fraction of ingested glucosinolates in adult beetles. Although these results show that $P$. armoraciae cannot fully prevent glucosinolate hydrolysis, we observed no negative influence on beetle performance. To understand how $P$. armoraciae can avoid the hydrolysis of some ingested glucosinolates, we analyzed their fate directly after ingestion. $P$. armoraciae rapidly absorbed glucosinolates across the gut epithelium, a strategy that has been proposed to prevent hydrolysis in the gut lumen of sequestering insects. Moreover, beetle gut content suppressed in vitro myrosinase activity, and almost no myrosinase activity was detectable in the feces, which indicates that ingested myrosinases are inactivated in the beetle gut. In summary, we show that $P$. armoraciae uses several strategies to prevent the hydrolysis of ingested glucosinolates but can also tolerate the formation of glucosinolate hydrolysis products.

Keywords: plant-insect interaction, plant defense, specialist herbivore, glucosinolate, myrosinase, adaptation, sequestration, excretion 


\section{Introduction}

Many plants deter herbivores with a chemical defense that is activated upon tissue damage (Morant et al., 2008). The chemical defense compound is usually stored as inactive glucose conjugate in the vacuole of plant cells. When plant tissue is damaged, the glucose moiety is hydrolyzed by a defensive $\beta$-glucosidase, originally localized separately from the glucose conjugate, which liberates toxic and deterrent compounds (Morant et al., 2008; Pentzold et al., 2014b). Activated chemical defenses are usually more efficient in deterring chewing herbivores that cause extensive tissue damage than in deterring insects with less invasive feeding modes, such as sap suckers (Pentzold et al., 2014b).

A number of herbivorous insects evolved resistance against this plant defense strategy (Pentzold et al., 2014b) and some highly adapted species even accumulate (sequester) plant glucosides in their bodies and deploy them for defense against predators (Kazana et al., 2007; Opitz and Müller, 2009; Beran et al., 2019). However, it is currently not well understood how chewing insects prevent the hydrolysis of ingested plant glucosides by plant $\beta$-glucosidases. A study with turnip sawfly larvae suggests that a rapid absorption of ingested glucosides (glucosinolates) across the gut epithelium prevents their hydrolysis in the gut; this is possibly facilitated by low plant $\beta$ glucosidase activity in the anterior gut (Abdalsamee et al., 2014). A rapid uptake mechanism was also proposed to enable western corn rootworm larvae, Diabrotica virgifera virgifera, to sequester benzoxazinoid glucosides; however, there was no evidence for reduced $\beta$-glucosidase activity in the larval gut (Robert et al., 2017). Burnet moth larvae which sequester cyanogenic glucosides avoid extensive plant $\beta$-glucosidase activity by a leaf-snipping feeding mode causing only minor tissue damage. Moreover, the common alkaline $\mathrm{pH}$ in the midgut lumen of lepidopteran larvae also inhibits plant $\beta$-glucosidase activity, whereas saliva extracts of burnet moth larvae did not prevent cyanogenic glucoside breakdown (Pentzold et al., 2014a).

Sequestering herbivores must avoid the hydrolysis of the ingested plant glucosides they sequester, but the extent to which plant $\beta$-glucosidase activity influences glucoside sequestration has rarely been assessed. The brassicaceous model plant Arabidopsis thaliana offers an ideal system to address this question. The activated defense of Arabidopsis and other plants of the order Brassicales is the glucosinolate-myrosinase system (Halkier and Gershenzon, 2006; Blažević et al., 2020). Glucosinolates are a structurally diverse group of amino acid-derived thioglucosides that are hydrolyzed by $\beta$-thioglucosidases called myrosinases. The resulting aglucone is unstable and rearranges spontaneously into a highly reactive isothiocyanate, which is toxic for small herbivores (Jeschke et al., 2016a). The Arabidopsis tgg1×tgg2 double knock-out mutant mutant (tgg) is devoid of myrosinase activity in leaves (Barth and Jander, 2006) and thus can be used for comparative feeding studies with the corresponding Arabidopsis Col-0 wild type (wild type). For example, in feeding experiments performed with the cabbage stem flea beetle, Psylliodes chrysocephala, adult beetles sequestered six times more glucosinolates from the myrosinasedeficient Arabidopsis tgg mutant than from the wild type (Beran et al., 2018). In a similar feeding experiment performed with larvae of the horseradish flea beetle, Phyllotreta armoraciae, only traces of sequestered glucosinolates were detected in wild type-fed larvae, whereas comparatively high glucosinolate levels were found in $t g g$-fed larvae (Sporer et al., 2020). In contrast to $P$. armoraciae larvae, adult beetles were able to sequester glucosinolates from wild type leaves (Yang et al., 2020), which suggests that plant myrosinase activity has a stronger influence on glucosinolate sequestration in larvae compared to adults. Plant myrosinase activity influences not 
only sequestration, but also the feeding behavior of Phyllotreta flea beetles. In field experiments, the crucifer flea beetle, Phyllotreta cruciferae, caused less feeding damage on Brassica rapa plants selected for high myrosinase activity than on plants selected for low myrosinase activity (Siemens and Mitchell-Olds, 1996).

Here, we investigated the influence of plant myrosinase activity on glucosinolate sequestration in the adult life stage of $P$. armoraciae. In a previous feeding study, we recovered about $35 \%$ of the total ingested glucosinolates from wild type leaves in the beetle body and feces, whereas the metabolic fate of more than $60 \%$ of the total ingested glucosinolates remained unknown (Yang et al., 2020). One possible explanation is that the unrecovered glucosinolates were hydrolyzed by plant myrosinases. To investigate this possibility, we performed a series of comparative feeding experiments with myrosinase-deficient and wild type Arabidopsis plants. In nature, $P$. armoraciae is closely associated with horseradish, Armoracia rusticana, a plant species that is characterized by high levels of allyl glucosinolate (Li and Kushad, 2004; Ciska et al., 2017). Therefore, we additionally investigated the influence of plant myrosinase activity on the sequestration of allyl glucosinolate by spiking the intact glucosinolate into Arabidopsis leaves. We observed a negative influence of plant myrosinase activity on glucosinolate sequestration and confirmed that a fraction of ingested glucosinolates is hydrolysed in P. armoraciae. We thus asked whether the metabolism of glucosinolate hydrolysis products incurs a metabolic cost in P. armoraciae. Finally, we explored possible mechanisms that allow $P$. armoraciae to partially prevent the hydrolysis of ingested glucosinolates by plant myrosinase.

\section{Materials and Methods}

\section{$98 \quad$ Plants and insects}

99 Food plants, Brassica juncea cv. "Bau Sin" and Brassica rapa cv. "Yu-Tsai-Sum" (Known-You 100 Seed Co., Ltd., Taiwan) were cultivated in a controlled environment chamber $\left(24{ }^{\circ} \mathrm{C}, 55 \%\right.$ relative 101 humidity, 14-h light/10-h dark period). Arabidopsis thaliana plants were cultivated under short 102 day conditions in a controlled environment chamber $\left(2{ }^{\circ} \mathrm{C}, 55 \%\right.$ relative humidity, 10-h light/14-h 103 dark period). The following genotypes were used: A. thaliana Col-0 (wild type), the myrosinase 104 deficient A. thaliana tgg $1 \times \operatorname{tgg} 2$ (tgg) double knockout mutant (Barth and Jander, 2006), and the 105 A. thaliana myb28×myb29 (myb) double knockout mutant which does not produce aliphatic 106 glucosinolates (Sønderby et al., 2007).

Phyllotreta armoraciae was reared on potted three- to four-week old B. juncea or B. rapa plants in a controlled environment chamber $\left(24{ }^{\circ} \mathrm{C}, 60 \%\right.$ relative humidity, 14-h light/10-h dark period). Adult beetles were provided with new plants every week and plants with eggs were kept separately

110 for larval development. After three weeks, any remaining plant material was removed and the soil 111 containing pupae was kept in plastic containers (9 L volume, Lock\&Lock). Newly emerged adults 112 were collected every two to three days. Unless stated otherwise, experiments were performed with 113 newly emerged beetles that had been reared on B. juncea plants.

\section{Sequestration experiments}

115 To analyze whether plant myrosinase activity influences the sequestration of glucosinolates in $116 P$. armoraciae beetles, we performed sequestration experiments with the myrosinase-deficient 117 Arabidopsis tgg mutant and the corresponding wild type Col-0. 
In Experiment 1, we fed newly emerged beetles for one day with detached leaves of Arabidopsis wild type or tgg plants ( $\mathrm{n}=28$ per genotype, two beetles per replicate). On the next day, the remaining leaves were weighed, frozen in liquid nitrogen, and stored at $-20{ }^{\circ} \mathrm{C}$ until they were freeze dried. To allow for metabolism of ingested aliphatic glucosinolates, we fed the beetles one additional day on Arabidopsis myb leaves before beetles were weighed, frozen in liquid nitrogen, and stored at $-20{ }^{\circ} \mathrm{C}$ until extraction. The extraction and analysis of glucosinolates by high performance liquid chromatography coupled with diode array detection (HPLC-DAD) was performed as described in Beran et al. (2014). Adult $P$. armoraciae beetles convert ingested 4methylsulfinylbutyl (4MSOB) glucosinolate, the major aliphatic glucosinolate in Arabidopsis wild type and tgg plants, into 4-methylthiobutyl (4MTB) glucosinolate (Yang et al., 2020). Therefore, we summed up the concentrations of 4MSOB and 4MTB glucosinolate in each beetle sample and expressed this concentration relative to that of both glucosinolates in the corresponding leaf sample, which was set to $100 \%$. To confirm that beetles feed equally on both Arabidopsis lines, we quantified the beetle feeding damage ( 2 beetles per leaf disc with $16 \mathrm{~mm}$ diameter) over one day using the software Fiji (Schindelin et al., 2012) ( $\mathrm{n}=8$ per genotype).

In Experiment 2, we fed newly emerged beetles with Arabidopsis wild type, $t g g$, or myb leaves for one day ( $\mathrm{n}=5$, with 5 beetles per replicate). Afterwards, feces were collected in $50 \mu \mathrm{L}$ ultrapure water containing $0.1 \%(\mathrm{v} / \mathrm{v})$ formic acid, mixed with $50 \mu \mathrm{L}$ pure methanol and stored at $-20{ }^{\circ} \mathrm{C}$. Beetles were frozen in liquid nitrogen and stored at $-20{ }^{\circ} \mathrm{C}$ until extraction. Remaining leaves were weighed, frozen in liquid nitrogen and freeze-dried. Feces samples were homogenized for 2 min at $25 \mathrm{~Hz}$ in a TissueLyzerII (Qiagen) using metal beads. Beetles were homogenized in $500 \mu \mathrm{L}$ $50 \%$ (v/v) methanol using plastic pestles. Freeze-dried leaves were homogenized to powder as described for feces samples and extracted with $800 \mu \mathrm{L}$ of $50 \%(\mathrm{v} / \mathrm{v})$ methanol. Samples were centrifuged at $4{ }^{\circ} \mathrm{C}$ for $10 \mathrm{~min}$ at $16,000 \times \mathrm{g}$ and supernatants were stored at $-20{ }^{\circ} \mathrm{C}$ until analysis by liquid chromatography coupled with tandem mass spectrometry (LC-MS/MS). Identification and quantification of $4 \mathrm{MSOB}$ glucosinolate and 4MSOB glucosinolate-derived metabolites in samples was performed as described in Beran et al. (2018). After quantification, we subtracted the average amounts of each metabolite in bodies or feces of $m y b$-fed control beetles (background control) from those detected in wild type- or tgg-fed beetles.

In Experiment 3, we fed newly emerged beetles for one day with Arabidopsis wild type or $\operatorname{tg} g$ leaves that were each spiked with $300 \mathrm{nmol}$ allyl glucosinolate (Carl Roth) as described in Schramm et al. (2012). This experiment was performed with adult beetles that had been reared on B. rapa plants, which do not produce allyl glucosinolate (Beran et al., 2018). The glucosinolate profile of unfed beetles reared on B. rapa was analyzed as described in Beran et al. (2014) $(n=20$, with 5 beetles per replicate) to confirm that allyl glucosinolate is not present in beetles. To prevent leaf wilting, we placed the petiole in a reaction tube filled with water. Newly emerged beetles were fed with spiked Arabidopsis leaves for one day ( $\mathrm{n}=10$ per genotype, 5 beetles per replicate) and allyl glucosinolate-spiked leaves without beetles were kept under the same conditions as a recovery control ( $\mathrm{n}=8$-10 per genotype). All leaf samples were frozen in liquid nitrogen, freeze-dried, and homogenized with metal beads (2.4 mm diameter, Askubal) for $2 \mathrm{~min}$ at $25 \mathrm{~Hz}$ in a TissueLyzerII (Qiagen). Beetles were weighed and frozen in liquid nitrogen. Feces were collected in $100 \mu \mathrm{L}$ ultrapure water and mixed with $100 \mu \mathrm{L}$ pure methanol. Leaf and beetle samples were homogenized in $1 \mathrm{~mL}$ and $800 \mu \mathrm{L} 50 \%(\mathrm{v} / \mathrm{v})$ methanol, respectively. After centrifugation for $10 \mathrm{~min}$ at $16,000 \times \mathrm{g}$, supernatants were collected. Feces samples were homogenized as described for leaves 162 and centrifuged at $4{ }^{\circ} \mathrm{C}$ or $10 \mathrm{~min}$ at $16,000 \times \mathrm{g}$. The supernatant was collected, the solvent 
evaporated using nitrogen and extracts were re-dissolved in $80 \mu \mathrm{L} 50 \%$ methanol. Samples were stored at $-20{ }^{\circ} \mathrm{C}$ until LC-MS/MS as described in Malka et al. (2016) using a modified elution gradient. The gradient consisted of formic acid $(0.2 \%)$ in water (solvent A) and acetonitrile (solvent B) and was carried out as follows: $1.5 \%(\mathrm{v} / \mathrm{v}) \mathrm{B}(1 \mathrm{~min}), 1.5-5 \%(\mathrm{v} / \mathrm{v}) \mathrm{B}(5 \mathrm{~min}), 5-7 \%$ (v/v) B (2 min), 7-12.6\% (v/v) B (4 min), 12.6-100\% (v/v) B (0.1 min), 100\% (v/v) B (0.9 min), 100 to $1.5 \%(\mathrm{v} / \mathrm{v}) \mathrm{B}(0.1 \mathrm{~min})$, and $1.5 \%(\mathrm{v} / \mathrm{v}) \mathrm{B}(3.85 \mathrm{~min})$. Allyl glucosinolate was quantified using an external calibration curve. We recovered $97.8 \pm 6.5 \%$ and $109.5 \pm 4.4 \%$ (mean \pm SD) of the spiked glucosinolate from undamaged (control) wild type and tgg leaves, respectively, showing that only small amounts of spiked allyl glucosinolate were metabolized in Arabidopsis leaves under our assay conditions. To determine how much allyl glucosinolate beetles had ingested, we subtracted the allyl glucosinolate amount detected in each fed leaf from the average allyl glucosinolate amounts recovered from corresponding unfed control leaves. The amounts of allyl glucosinolate that were recovered in beetles and feces were expressed relative to the total ingested amount, which was set to $100 \%$.

In Experiment 4, we fed newly emerged beetles with allyl glucosinolate-spiked Arabidopsis wild type or tgg leaves (prepared as described in Experiment 3) for one day and simultaneously collected the headspace on Porapak-Q ${ }^{\mathrm{TM}}$ volatile collection traps $(25 \mathrm{mg}$; ARS, Inc) ( $\mathrm{n}=6-7$ per genotype, 8 beetles per replicate). Leaves without beetles served as controls ( $n=4$ per genotype). The volatile collection and sample analysis by gas chromatography mass spectrometry (GC-MS) was performed as previously described in Sporer et al. (2020). Allyl isothiocyanate was quantified in headspace samples using an external calibration curve prepared from an authentic standard (Sigma-Aldrich). The glucosinolate amount per fed beetle was determined as described in

185 Experiment 1.

\section{Performance experiment}

To investigate whether the hydrolysis of ingested glucosinolates has a negative influence on beetle performance, we compared the fresh weight and energy reserves of beetles that had fed for ten days on Arabidopsis wild type or tgg leaf discs. We separated newly emerged beetles into males and females and assigned them randomly to one of the two Arabidopsis genotypes $(\mathrm{n}=10$ females per genotype, $\mathrm{n}=8-9$ males per genotype). Each beetle was provided with a new leaf cut from an undamaged Arabidopsis plant every day for ten consecutive days. After ten days feeding, beetles were weighed, frozen in liquid nitrogen, and stored at $-20^{\circ} \mathrm{C}$ until analysis of energy reserves. The contents of soluble protein, total lipids, glycogen and soluble carbohydrates in individual beetles were determined as described in Foray et al. (2012) with minor modifications. Instead of a 96-well borosilicate microplate, we used a 96-well quartz glass microplate (Hellma Analytics) that was covered with MicroAmp clear adhesive film (Applied Biosystems). The plate was heated using a ThermoMixer (Eppendorf) and for measurements we used a Tecan Infinite 200 Reader (Tecan). As a control, we quantified the levels of soluble protein, amino acids, and sugars in rosette leaves of Arabidopsis wild type and tgg mutant plants (for details refer to Supplementary Methods).

\section{Short-term feeding experiment}

202 In a short-term feeding experiment, we allowed newly emerged beetles to feed for 1 min on wild 203 type or $\operatorname{tgg}$ leaves. After $5 \mathrm{~min}$, beetles were dissected into gut and remaining body (without head; $204 \mathrm{n}=3,3$ beetles per replicate). Non-fed beetles were used as background control $(\mathrm{n}=2-3,3$ beetles 
per replicate). Dissected guts were washed twice in phosphate-buffered saline (PBS) pH 7.4 (BioRad) before sampling. Samples were homogenized in $500 \mu \mathrm{L} 80 \%$ methanol containing $0.4 \mu \mathrm{M}$ 4-hydroxybenzyl glucosinolate as internal standard using plastic pestles and stored at $-20{ }^{\circ} \mathrm{C}$ until extraction and analysis by LC-MS/MS as described above in Experiment 2. We quantified 4MSOB glucosinolate in each sample using an external standard curve and expressed the glucosinolate distribution in the gut and rest of the body relative to the total amount detected in both samples (set to $100 \%$ ).

\section{Myrosinase inhibition assays}

To determine whether $P$. armoraciae can inhibit ingested myrosinase activity, we performed myrosinase activity assays with gut content extracts of adult beetles. The gut content of adults was collected as follows: dissected guts were washed in extraction buffer $(20 \mathrm{mM} 2-(\mathrm{N}-$ morpholino)ethanesulfonic acid (MES), $\mathrm{pH}$ 5.2) containing protease inhibitors (cOmplete, EDTAfree) and cut open longitudinally to collect the gut content in $2.5 \mu \mathrm{L}$ of extraction buffer. For each sample, gut contents from 20 beetles were pooled, frozen in liquid nitrogen and stored at $-20{ }^{\circ} \mathrm{C}$ until extraction $(\mathrm{n}=4)$. Samples were homogenized with metal beads for 2 min at $25 \mathrm{~Hz}$ in a TissueLyzer II, centrifuged at $4{ }^{\circ} \mathrm{C}$ for $10 \mathrm{~min}$ at $16,000 \times g$ and the supernatant split into two subsamples of which one was boiled for $5 \mathrm{~min}$ at $99^{\circ} \mathrm{C}$.

Assays (50 $\mu \mathrm{L}$ total volume) consisted of $0.1 \mathrm{mM}$ ascorbic acid (Fluka, Buchs, Switzerland), $0.2 \mathrm{mM} 4 \mathrm{MSOB}$ glucosinolate (substrate), $0.5 \mathrm{ng} / \mu \mathrm{L}$ partially purified myrosinase from Sinapis alba (Sigma-Aldrich, details of protein purification are described in the Supplementary Methods) and a) gut content extract (corresponding to four beetles), b) boiled gut content extract, or c) extraction buffer (control). Assays with gut extracts but without myrosinase and assays containing only substrate were used as additional controls. Assays were incubated for $15 \mathrm{~min}$ at $30{ }^{\circ} \mathrm{C}$, the reaction was stopped by $5 \mathrm{~min}$ boiling at $99{ }^{\circ} \mathrm{C}$ and extracted with $100 \mu \mathrm{L} 80 \%$ methanol containing $0.2 \mathrm{mM}$ 4-hydroxybenzyl glucosinolate as an internal standard. Myrosinase activity was determined by quantifying the remaining $4 \mathrm{MSOB}$ glucosinolate amount in each assay as

\section{Detection of myrosinase enzyme and activity in beetle feces}

233 To determine whether $P$. armoraciae can degrade ingested plant myrosinase enzymes, we collected feces of 90 adults that had fed on Arabidopsis wild type leaves for one day in a total volume of $1 \mathrm{~mL} 20 \mathrm{mM}$ MES buffer $\mathrm{pH} 6.5$ containing protease inhibitors (cOmplete, EDTA-free, Roche). After homogenization with metal beads for $3 \mathrm{~min}$ at $25 \mathrm{~Hz}$ in a TissueLyzer II and centrifugation at $4{ }^{\circ} \mathrm{C}$ for $10 \mathrm{~min}$ at $16,000 \times \mathrm{g}$, we precipitated soluble proteins in the supernatant using trichloroacetic acid and washed the pellet with acetone. The protein pellet was dissolved in Laemmli buffer (Bio-Rad), boiled for $15 \mathrm{~min}$ at $95{ }^{\circ} \mathrm{C}$, and separated on a $12.5 \%$ Criterion Tris$\mathrm{HCl}$ precast gel (Bio-Rad). Protein bands were stained with colloidal Coomassie G250 (Carl Roth), excised from the gel, and digested with porcine trypsin (Promega) as described in Shevchenko et al. (2006). Samples were re-dissolved in $30 \mu \mathrm{L} 1 \%$ (v/v) formic acid and $2 \mu \mathrm{L}$ were analyzed by nano-UPLC-MS ${ }^{\mathrm{E}}$ analysis as described in Vassão et al. (2018). Data were acquired using dataindependent acquisition, referred to as enhanced $\mathrm{MS}^{\mathrm{E}}$. MS data were collected using MassLynx v4.1 software (Waters). 
The processing of nano-UPLC-MS ${ }^{\mathrm{E}}$ data and protein identification was performed as follows: the acquired continuum of LC-MS ${ }^{\mathrm{E}}$ data were processed using the ProteinLynx Global Server (PLGS) version 2.5.2 (Waters) to generate product ion spectra for database searching according to the ion accounting algorithm described in $\mathrm{Li}$ et al. (2009). Processed data were searched against a reference sequence (Refseq) database containing Arabidopsis thaliana sequences (40785 sequences, downloaded from the Identical Protein Groups database at the National Center for Biotechnology Information (NCBI, https://www.ncbi.nlm.nih.gov/ipg on February 28, 2020) combined with a subdatabase containing common contaminants (O'Leary et al., 2016). Database searching was performed at a false discovery rate (FDR) of $2 \%$ with the following parameters: minimum numbers of fragments per peptide (3), peptides per protein (1), fragments per protein (7), and maximum number of missed tryptic cleavage sites (1). Searches were restricted to tryptic peptides with a fixed carbamidomethylation of cysteine residues along with variable oxidation of methionine. Proteins were classified according to the algorithm described for PAnalyzer software (Prieto et al., 2012) and divided into four groups: conclusive, indistinguishable, ambiguous, and non-conclusive. Conclusive and indistinguishable hits were considered as confident matches.

To determine whether $P$. armoraciae excretes active myrosinase enzyme, we analyzed myrosinase activity in feces homogenates and compared this activity with the corresponding ingested myrosinase activity in leaves. We used newly emerged $P$. armoraciae beetles that had been reared on B. rapa, and fed them for one day with $m y b$ leaves containing myrosinase activity but no 4MSOB glucosinolate $(n=6$, with 6 beetles per replicate). Leaves were weighed before and after feeding to determine the ingested plant fresh weight. Leaves were supplied with water during the experiment and the average proportional weight gain of intact leaves was used to correct the initial leaf weight $(\mathrm{n}=16)$. Feces from each replicate were collected in $130 \mu$ l extraction buffer $(20 \mathrm{mM}$ MES buffer, $\mathrm{pH}$ 6.5, containing protease inhibitors (cOmplete, EDTA-free)). Feces and fed leaves were frozen in liquid nitrogen and stored at $-80{ }^{\circ} \mathrm{C}$ until extraction. Feces samples were homogenized with metal beads at $25 \mathrm{~Hz}$ for $2 \mathrm{~min}$ in a TissueLyzer II. The corresponding frozen leaf samples were homogenized with metal beads at $25 \mathrm{~Hz}$ for $2 \mathrm{~min}$ in a pre-cooled sample holder to prevent thawing. For each replicate, we calculated the ingested fresh weight and extracted the corresponding amount of homogenized plant tissue in the same buffer volume used for feces extraction. After centrifugation at $4{ }^{\circ} \mathrm{C}$ for $10 \mathrm{~min}$ at $16,000 \times \mathrm{g}$, the supernatant was directly used for myrosinase activity assays. Assays consisted of $25 \mu \mathrm{L}$ extraction buffer, $5 \mu \mathrm{L}$ of an aqueous $11 \mathrm{mM} 4 \mathrm{MSOB}$ glucosinolate solution, and a) $25 \mu \mathrm{L}$ feces homogenate or b) $25 \mu \mathrm{L}$ leaf extract. Assays containing only extraction buffer and substrate served as background control $(\mathrm{n}=3)$. To test whether feces extracts have an inhibitory effect on plant myrosinase activity, we additionally performed assays in which we mixed $25 \mu \mathrm{L}$ of feces homogenate with $25 \mu \mathrm{L}$ of corresponding leaf extract and glucosinolate substrate. Except for three assays with combined feces and leaf extracts, all assays were performed with two technical replicates. Assays were incubated for 30 min at 30 ${ }^{\circ} \mathrm{C}$, stopped by boiling for $5 \mathrm{~min}$ at $95^{\circ} \mathrm{C}$, and $50 \mu \mathrm{L}$ of $60 \%(\mathrm{v} / \mathrm{v})$ methanol were added. After the activity assay, samples containing feces homogenates were centrifuged at $4{ }^{\circ} \mathrm{C}$ for $10 \mathrm{~min}$ at $16,000 \times \mathrm{g}$, the supernatant collected and final samples were stored at $-20{ }^{\circ} \mathrm{C}$ until LC-MS/MS

286 analysis. 4MSOB glucosinolate was quantified as described in Experiment 2 and myrosinase 287 activity was expressed as nmol 4MSOB hydrolyzed per minute and mg (ingested) plant fresh 288 weight. 
Statistical analyses were performed in R3.3.1 (R Core Team, 2018) or in SigmaPlot 11.0 (Systat Software). Details of statistical analyses performed for each dataset are summarized in 292 Supplementary Table 1.

\section{RESULTS}

\section{Plant myrosinase activity influences glucosinolate sequestration}

We examined the influence of plant myrosinase activity on glucosinolate sequestration by feeding P. armoraciae adults with Arabidopsis leaves with (wild type) or without (tgg) myrosinase activity (Experiment 1 ). Because $P$. armoraciae converts sequestered 4MSOB glucosinolate into 4MTB glucosinolate (Yang et al. 2020), we quantified the levels of both 4MSOB and 4MTB glucosinolate in beetles relative to those in the food plant and found that $t g g$-fed beetles accumulated twofold higher levels of glucosinolates than wild type-fed beetles (Mann-Whitney rank sum test, $U=$ $482.000, p<0.001$; Figure 1A). Since beetle feeding rates and glucosinolate levels did not differ between treatments (feeding rate: Student's $t$-test, $t=0.592, p=0.564$; plant glucosinolates level: Mann-Whitney rank sum test, $U=390.000, p=0.980$ ), our results demonstrate a negative impact of plant myrosinase activity on glucosinolate sequestration in P. armoraciae.

To determine whether the lower 4MSOB glucosinolate accumulation rate in wild type- compared to $t g g$-fed beetles is due to hydrolysis, we quantified the levels of 4MSOB glucosinolate and known hydrolysis products in bodies and feces of wild type- and tgg-fed beetles by LC-MS/MS (Experiment 2). We found that the detected metabolite levels differed greatly between replicates (Supplementary Table 2), despite similar 4MSOB glucosinolate concentrations in wild type- and tgg-leaves (Student's $t$-test, $t=0.371, p=0.720$ ). We thus compared the relative composition of metabolites between treatments and found significantly higher percentages of hydrolysis products in body and feces samples of wild type-fed beetles than in the corresponding samples of tgg-fed beetles (Figure 1B; results of statistical analyses are summarized in Supplementary Table 1). 4MSOB cyanide represented the dominant hydrolysis product in body and feces samples whereas only traces of free and metabolized isothiocyanates were detected (Supplementary Table 2, Figure 1B). Overall, glucosinolate hydrolysis products accounted for $28 \%$ and $2.2 \%$ of the total detected metabolites in wild type- and tgg-fed beetles, respectively (bodies and feces). Together, our results show that a fraction of ingested $4 \mathrm{MSOB}$ glucosinolate was hydrolyzed by the plant myrosinase, but that glucosinolate hydrolysis also occurred independently of plant myrosinase activity.

To directly quantify the impact of plant myrosinase activity on the metabolic fate of ingested glucosinolates in $P$. armoraciae, we performed a feeding experiment with wild type- and tggleaves that were spiked with allyl glucosinolate, the major glucosinolate of the natural host plant of $P$. armoraciae (Experiment 3). This experiment was performed with adult beetles that were reared on B. rapa plants and, therefore, do not contain allyl glucosinolate (Supplementary Table 3). Tgg-fed beetles accumulated a significantly higher proportion of ingested allyl glucosinolate than wild type-fed beetles (Table 1). Plant myrosinase activity explained the fate of $9 \%$ of the ingested allyl glucosinolate; however, the metabolic fate of $47 \%$ and $56 \%$ of the ingested allyl glucosinolate in $\operatorname{tgg}$ - and wild type-fed beetles remained unknown, respectively (Table 1).

To confirm that ingested allyl glucosinolate is hydrolyzed, we quantified the emission of the volatile glucosinolate hydrolysis product allyl isothiocyanate during beetle feeding (Experiment 
4). We detected significantly higher amounts of allyl isothiocyanate in the headspace samples of wild type-fed beetles as compared to tgg-fed beetles, while the levels of sequestered allyl glucosinolate were not influenced by the food plant (Figure 2; results of statistical analyses are summarized in Supplementary Table 1).

Plant myrosinase activity does not affect beetle weight and energy reserves

To determine whether the hydrolysis of ingested glucosinolates by plant myrosinase influences beetle performance, we compared the beetle fresh weight and the levels of soluble proteins, carbohydrates, glycogen and lipids in beetles that were fed with Arabidopsis leaves with and without myrosinase activity for ten days. The food plant had no influence on the beetle weight or energy reserves, indicating that $P$. armoraciae adults can tolerate the partial hydrolysis of ingested glucosinolates (Supplementary Table 4). As a control, we compared the nutritional value of wild type and $\operatorname{tg} g$ leaves and also found no differences regarding the total levels of soluble protein, free amino acids, soluble sugars and glucosinolates between these genotypes (Supplementary Table 5).

$P$. armoraciae rapidly sequesters glucosinolates and suppresses plant myrosinase activity in the gut

The rapid absorption of ingested glucosinolates across the gut epithelium represents one possible mechanism to prevent hydrolysis in the gut lumen. We analyzed the distribution of ingested glucosinolates in P. armoraciae beetles $5 \mathrm{~min}$ after feeding on wild type and tgg leaves and recovered more than $80 \%$ of the total detected $4 \mathrm{MSOB}$ glucosinolate from the body (without gut). The relative distribution of detected glucosinolates did not differ between wild type- and tgg-fed beetles (Student's $t$-test, $t=0.075, p=0.944$, Figure 3A). To determine whether glucosinolate sequestration is facilitated by suppression of plant myrosinase activity in the gut lumen of $P$. armoraciae, we analyzed the influence of beetle gut content extracts on activity of partially purified $S$. alba myrosinase in in vitro assays. Compared to control assays, gut content extracts significantly reduced myrosinase activity by up to $50 \%$ (ANOVA, $F=85.639, p<0.001$ ). Boiled gut content extracts reduced myrosinase activity significantly less than untreated extracts (Figure 3B).

\section{P. armoraciae excretes inactive myrosinase enzyme}

359 To investigate whether the Arabidopsis myrosinases TGG1 and TGG2 are degraded in the gut of $P$. armoraciae, we analyzed the fecal proteome by nano-UPLC-MS ${ }^{\mathrm{E}}$. We detected a total of 14 peptides derived from the Arabidopsis myrosinase TGG1 in two protein bands between 55 and 70 $\mathrm{kDa}$ that covered 34\% of the TGG1 amino acid sequence (Figure 4A, B; Supplementary Table 6). The molecular weight range in which we detected TGG1 peptides corresponds approximately to the predicted $(61.1 \mathrm{kDa})$ and apparent $(75 \mathrm{kDa})$ molecular weight of TGG1 (Zhou et al., 2012). TGG2-specific peptides were not detected in beetle feces with our approach (Supplementary Data $1)$.

Since the proteomic analysis indicates that $P$. armoraciae excretes intact myrosinase, we compared the levels of ingested myrosinase activity with those that were excreted. Myrosinase activity detected in feces corresponded to less than $4 \%$ of the ingested activity (Figure 5, $t=10.449, p<$ 0.005). We additionally spiked plant myrosinase extracts into feces homogenates, but observed similar activity as in control assays (Figure $5, t=0.158, p=1.000$ ). 


\section{DISCUSSION}

373 The enzymatic activity of defensive plant $\beta$-glucosidases is a major barrier to the sequestration of 374 plant glucosides by herbivorous insects (Morant et al., 2008; Pentzold et al., 2014b). Here, we investigated the impact of plant myrosinase activity on the sequestration of glucosinolates in $P$. armoraciae and explored possible mechanisms that enable adult beetles to suppress glucosinolate hydrolysis during feeding and digestion. We demonstrate a negative influence of plant myrosinase activity on sequestration and confirmed that a fraction of ingested glucosinolates is hydrolyzed by plant myrosinases. We found two mechanisms that can reduce the glucosinolate hydrolysis rate in the gut: the rapid absorption of ingested glucosinolates across the gut epithelium and the suppression of plant myrosinase activity in the gut lumen.

Compared to previous studies with P. chrysocephala adults (Beran et al., 2018; Ahn et al., 2019), plant myrosinase activity had less impact on the metabolic fate of ingested glucosinolates in $P$. armoraciae adults. In quantitative studies, plant myrosinases hydrolyzed approximately $75 \%$ of the total ingested glucosinolates in P. chrysocephala, whereas only about $10 \%$ of ingested allyl glucosinolate were hydrolyzed in $P$. armoraciae. Although $P$. chrysocephala and $P$. armoraciae belong to different genera, they have similar body sizes and feeding modes and therefore cause comparable feeding damage. Our results thus indicate that $P$. armoraciae adults are better adapted to overcome plant myrosinase activity than $P$. chrysocephala adults.

Plant myrosinases hydrolyzed a fraction of ingested glucosinolates in $P$. armoraciae and thus negatively influenced glucosinolate sequestration (Figure 1 and 2, Table 1). Although the sequestration rates of $4 \mathrm{MSOB}$ glucosinolate and allyl glucosinolate cannot be compared directly because different methods were used for quantification, our results indicate a stronger influence of plant myrosinase activity on 4MSOB glucosinolate than on allyl glucosinolate. Biochemical studies with Arabidopsis myrosinases TGG1 and TGG2 revealed similar activities of both enzymes towards these two glucosinolates (Zhou et al., 2012), making it unlikely that the substrate preferences of Arabidopsis myrosinases affected sequestration. A similar glucosinolate-dependent effect of plant myrosinase activity on sequestration was also observed in $P$. armoraciae larvae (Sporer et al., 2020). Larvae sequestered allyl glucosinolate from B. juncea leaves but almost no glucosinolates from Arabidopsis wild type leaves, despite similar levels of soluble myrosinase activity in both plant species. Thus, the metabolic fate of ingested allyl glucosinolate in P. armoraciae appears to be less affected by plant myrosinase activity than that of Arabidopsis glucosinolates. Since allyl glucosinolate represents the dominant glucosinolate in horseradish, $404 P$. armoraciae might have developed specific mechanisms to avoid the hydrolysis of the characteristic glucosinolate of its natural host plant (Li and Kushad, 2004).

Glucosinolate hydrolysis products, in particular isothiocyanates, are well-known to have a negative impact on insect growth and development by interfering with nutrition (Agrawal and Kurashige, 2003; Jeschke et al., 2016b; Jeschke et al., 2017; Sun et al., 2019). Under our experimental conditions, the hydrolysis of ingested glucosinolates by plant myrosinases did not influence the weight or energy reserves of $P$. armoraciae adults. In addition, we observed no effect of plant myrosinase activity on developmental time, weight, and energy reserves of $P$. armoraciae larvae 412 (for details refer to Supplementary Materials and Supplementary Table 9). The exposure to 413 glucosinolate hydrolysis products could influence other fitness parameters such as female 
fecundity or egg hatching rate (Sun et al., 2019); however, our current results indicate that $P$. armoraciae can tolerate glucosinolate hydrolysis without a major impact on beetle performance.

416 Previous feeding experiments performed with generalist lepidopteran herbivores revealed 4MSOB 417 isothiocyanate to be the major hydrolysis product of 4MSOB glucosinolate in Arabidopsis 418 (Schramm et al., 2012; Jeschke et al., 2017). However, we detected much more 4MSOB cyanide in $P$. armoraciae bodies and feces relative to $4 \mathrm{MSOB}$ isothiocyanate and its derivatives (Figure 1B). There are several possible explanations for this unexpected result: 4MSOB isothiocyanate may not have been recovered completely with our extraction methods because it reacted with proteins or was metabolized by the beetle or associated gut microbes (Brown and Hampton, 2011; Jeschke et al., 2015; van den Bosch and Welte, 2017; Friedrichs et al., 2020; Shukla and Beran, 2020). Alternatively, P. armoraciae may be able to manipulate the outcome of glucosinolate hydrolysis and promote the formation of less toxic 4MSOB cyanide instead of 4MSOB isothiocyanate. Manipulation of glucosinolate hydrolysis occurs for example in larvae of the cabbage white butterfly, which express a so-called nitrile specifier protein in the gut (Wittstock et al., 2004). In fact, a redirection of glucosinolate hydrolysis towards less toxic nitriles could explain why plant myrosinase activity had no measurable effect on $P$. armoraciae performance. Further research is needed to understand the mechanism underlying the unusual composition of glucosinolate hydrolysis products in $P$. armoraciae.

How chewing insects that cause extensive tissue damage prevent the hydrolysis of ingested plant glucosides is currently not well understood. One proposed mechanism is a rapid absorption of plant glucosides across the gut epithelium that separates substrate and enzyme (Abdalsamee et al., 2014; Pentzold et al., 2014b; van Geem et al., 2014). Indeed, already after few minutes, we detected most ingested glucosinolates in the beetle body (without gut). This shows that glucosinolate uptake occurs rapidly in $P$. armoraciae, but it is unclear whether this prevents glucosinolate hydrolysis in the gut lumen. Moreover, we had expected to find less glucosinolates in the guts of wild type-fed beetles due to the presence of myrosinase activity, but we recovered similar proportions of glucosinolates in the guts of tgg- and wild type-fed beetles. However, we cannot rule out that glucosinolates detected in the gut were spatially separated from plant myrosinases, either in remaining intact plant tissue or in the gut epithelium.

Another explanation for the detection of glucosinolates in the gut of $P$. armoraciae is the inhibition of plant myrosinase activity in the gut. We found that gut content extracts reduced plant myrosinase activity by 30 to $50 \%$ in in vitro assays, with boiled extracts inhibiting myrosinase activity significantly less than untreated extracts. These results provide direct evidence for suppression of myrosinase activity in the gut of $P$. armoraciae and indicate that several factors contribute to myrosinase inhibition, of which some are sensitive to heat. Candidate agents that can modify plant myrosinase activity include ascorbic acid (cofactor of myrosinases), sulfate, sodium chloride and silver ions (Shikita et al., 1999; Andersson et al., 2009; Bhat and Vyas, 2019; Marcinkowska and Jelen, 2020). In addition, the gut $\mathrm{pH}$ can have a strong influence on the activity of ingested plant enzymes (Pentzold et al., 2014b). For example, the highly alkaline pH of the midgut lumen of burnet moth larvae drastically reduced cyanogenic $\beta$-glucosidase activity in Lotus corniculatus leaf macerates (Pentzold et al., 2014a). In contrast, the neutral pH of gut homogenates of glucosinolate-sequestering turnip sawfly larvae had only minor influence on ingested plant myrosinase activity (Abdalsamee et al., 2014). In P. armoraciae, gut homogenates showed an 
acidic $\mathrm{pH}$ (details are described in the Supplementary Material), which is unlikely to have a strong influence on plant myrosinase activity.

459 Myrosinase from $S$. alba and other defensive $\beta$-glucosidases were largely resistant to digestion in the larval gut of the generalist lepidopteran Spodoptera littoralis and thus retained most of the activity after digestion (Vassão et al., 2018). Our proteomic analysis of beetle feces also indicates that Arabidopsis myrosinase TGG1 resisted digestion in $P$. armoraciae, whereas TGG2 was not detected in feces (Figure 4, Supplementary Table 7). Because TGG2 expression is restricted to phloem-associated cells (Barth and Jander, 2006), beetles likely ingested much less TGG2 than TGG1 by avoiding the leaf midrib and veins (personal observation). Despite the detection of TGG1 enzyme, we found almost no myrosinase activity in feces of $P$. armoraciae. We tested for the presence of myrosinase inhibitor(s) in feces homogenates but observed no suppression of spiked myrosinase activity under our assay conditions (Figure 5). Thus, we hypothesize that ingested TGG1 has been inactivated during gut passage in $P$. armoraciae. Previous studies with the turnip sawfly and the diamondback moth also indicated that plant myrosinases are not fully active in the gut (Abdalsamee et al., 2014; Sun et al., 2019). However, the underlying mechanism(s) of myrosinase inhibition in the gut of specialist herbivores including $P$. armoraciae remain to be determined.

P. armoraciae possesses endogenous myrosinase activity, which enables this specialist to exploit sequestered glucosinolates for defense against predators (Sporer et al. 2020). Our study provides first evidence that beetle myrosinases also contribute to glucosinolate metabolism in both adults (Figure 1B) and larvae (refer to Supplementary Materials, Supplementary Table 8 and Supplementary Figure 1). For example, $P$. armoraciae adults emitted the volatile hydrolysis product allyl isothiocyanate during feeding on myrosinase-deficient tg g leaves containing allyl glucosinolate. Volatile hydrolysis products derived from sequestered glucosinolates have also been detected in the headspace of the striped flea beetle, Phyllotreta striolata, which led to the initial discovery of a glucosinolate-myrosinase defense system in Phyllotreta flea beetles (Beran, 2011; Beran et al., 2014). To investigate the role of the beetle myrosinase in glucosinolate metabolism and defense in $P$. armoraciae, we currently perform experiments using beetles with suppressed myrosinase activity.

\section{CONCLUSION}

487 Defensive plant $\beta$-glucosidases represent a major target of herbivore adaptation to two-component 488 chemical defenses. Our study demonstrates that a specialist herbivore, $P$. armoraciae, can prevent the hydrolysis of glucosinolates using at least two strategies, the rapid absorption of the glucosinolates across the gut epithelium and the inhibition of plant myrosinase activity in the gut lumen. However, we also found that $P$. armoraciae can tolerate glucosinolate hydrolysis and is thus well-adapted to the chemical defense in its brassicaceous host plants.

494 The authors declare that the research was conducted in the absence of any commercial or financial 495 relationships that could be construed as a potential conflict of interest. 
497 TS, JK, and FB designed experiments, TS, JK, YH and FB performed experiments, TS, JK, MR, 498 NW and FB analyzed data, SGJ performed bioinformatic analyses, TS, JK, and FB wrote the 499 manuscript.

\section{$500 \quad$ FUNDING}

501 This project was supported by the Max Planck Society and the International Max Planck Research 502 School.

\section{ACKNOWLEDGEMENTS}

504 We thank the greenhouse team at the Max Planck Institute for Chemical Ecology for plant 505 cultivation, Susanne Donnerhacke, Alexander Schilling, Fabian Seitz, and Leopold Wohlsperger 506 for help with the rearing and experiments, Grit Kunert for help with statistical analyses, Daniel 507 Veit and the workshop team for technical support, Caroline Müller and Helga Pankoke (University 508 of Bielefeld) for help with the gut $\mathrm{pH}$ measurements, Sarah Wolf (Agroscope, Switzerland) for 509 lending equipment for the energy budget analysis, and Felix Feistel for discussions.

\section{DATA AVAILABILITY STATEMENT}

511 Source data of this study is available at the open access data repository of the Max Planck Society 512 (Edmond) under https://dx.doi.org/10.17617/3.5b. 


\section{REFERENCES}

514

Abdalsamee, M.K., Giampà, M., Niehaus, K., and Müller, C. (2014). Rapid incorporation of glucosinolates as a strategy used by a herbivore to prevent activation by myrosinases. Insect Biochem Mol Biol 52, 115-123.

Agrawal, A.A., and Kurashige, N.S. (2003). A role for isothiocyanates in plant resistance against the specialist herbivore Pieris rapae. Journal of Chemical Ecology 29, 1403-1415.

Ahn, S.-J., Betzin, F., Gikonyo, M.W., Yang, Z.-L., Köllner, T.G., and Beran, F. (2019). Identification and evolution of glucosinolate sulfatases in a specialist flea beetle. Scientific Reports 9, 15725.

Andersson, D., Chakrabarty, R., Bejai, S., Zhang, J., Rask, L., and Meijer, J. (2009). Myrosinases from root and leaves of Arabidopsis thaliana have different catalytic properties. Phytochemistry 70, 1345-1354.

Barth, C., and Jander, G. (2006). Arabidopsis myrosinases TGG1 and TGG2 have redundant function in glucosinolate breakdown and insect defense. The Plant Journal 46, 549-562.

Beran, F. (2011). Host preference and aggregation behavior of the striped flea beetle, Phyllotreta striolata. PhD Thesis, Humboldt-Universität, Berlin.

Beran, F., Köllner, T.G., Gershenzon, J., and Tholl, D. (2019). Chemical convergence between plants and insects: biosynthetic origins and functions of common secondary metabolites. New Phytol.

Beran, F., Pauchet, Y., Kunert, G., Reichelt, M., Wielsch, N., Vogel, H., Reinecke, A., Svatoš, A., Mewis, I., Schmid, D., Ramasamy, S., Ulrichs, C., Hansson, B.S., Gershenzon, J., and Heckel, D.G. (2014). Phyllotreta striolata flea beetles use host plant defense compounds to create their own glucosinolate-myrosinase system. Proceedings of the National Academy of Sciences 111, 7349-7354.

Beran, F., Sporer, T., Paetz, C., Ahn, S.-J., Betzin, F., Kunert, G., Shekhov, A., Vassão, D.G., Bartram, S., Lorenz, S., and Reichelt, M. (2018). One pathway is not enough: The cabbage stem flea beetle Psylliodes chrysocephala uses multiple strategies to overcome the glucosinolate-myrosinase defense in its host plants. Frontiers in Plant Science 9, 1754.

Bhat, R., and Vyas, D. (2019). Myrosinase: insights on structural, catalytic, regulatory, and environmental interactions. Critical Reviews in Biotechnology 39, 508-523.

Blažević, I., Montaut, S., Burčul, F., Olsen, C.E., Burow, M., Rollin, P., and Agerbirk, N. (2020). Glucosinolate structural diversity, identification, chemical synthesis and metabolism in plants. Phytochemistry 169, 112100.

Brown, K.K., and Hampton, M.B. (2011). Biological targets of isothiocyanates. Biochim Biophys Acta 1810, 888-894.

Ciska, E., Horbowicz, M., Rogowska, M., Kosson, R., Drabińska, N., and Honke, J. (2017). Evaluation of seasonal variations in the glucosinolate content in leaves and roots of four european horseradish (Armoraica rusticana) landraces. Polish Journal of Food and Nutrition Sciences 67, 301-308. 
Foray, V., Pelisson, P.-F., Bel-Venner, M.-C., Desouhant, E., Venner, S., Menu, F., Giron, D., and Rey, B. (2012). A handbook for uncovering the complete energetic budget in insects: the van Handel's method (1985) revisited. Physiological Entomology 37, 295-302.

Friedrichs, J., Schweiger, R., Geisler, S., Mix, A., Wittstock, U., and Müller, C. (2020). Novel glucosinolate metabolism in larvae of the leaf beetle Phaedon cochleariae. Insect Biochemistry and Molecular Biology 124, 103431.

Halkier, B.A., and Gershenzon, J. (2006). Biology and biochemistry of glucosinolates. Annu Rev Plant Biol 57, 303-333.

Jeschke, V., Gershenzon, J., and Vassão, D.G. (2015). "Metabolism of Glucosinolates and Their Hydrolysis Products in Insect Herbivores," in Recent Advances Phytochemistry: The formation, structure and activity of phytochemicals, ed. R. Jetter. (Switzerland: Springer International Publishing), 163-194.

Jeschke, V., Gershenzon, J., and Vassão, D.G. (2016a). "Chapter eight - Insect detoxification of glucosinolates and their hydrolysis products," in Advances in Botanical Research, ed. S. Kopriva. Academic Press), 199-245.

Jeschke, V., Gershenzon, J., and Vassão, D.G. (2016b). A mode of action of glucosinolate-derived isothiocyanates: Detoxification depletes glutathione and cysteine levels with ramifications on protein metabolism in Spodoptera littoralis. Insect Biochem Mol Biol 71, 37-48.

Jeschke, V., Kearney, E.E., Schramm, K., Kunert, G., Shekhov, A., Gershenzon, J., and Vassão, D.G. (2017). How glucosinolates affect generalist lepidopteran larvae: growth, development and glucosinolate metabolism. Front Plant Sci 8, 1995.

Kazana, E., Pope, T.W., Tibbles, L., Bridges, M., Pickett, J.A., Bones, A.M., Powell, G., and Rossiter, J.T. (2007). The cabbage aphid: a walking mustard oil bomb. Proceedings of the Royal Society of London. Series B: Biological Sciences 274, 2271-2277.

Li, G.-Z., Vissers, J.P.C., Silva, J.C., Golick, D., Gorenstein, M.V., and Geromanos, S.J. (2009). Database searching and accounting of multiplexed precursor and product ion spectra from the data independent analysis of simple and complex peptide mixtures. PROTEOMICS 9, 1696-1719.

Li, X., and Kushad, M.M. (2004). Correlation of glucosinolate content to myrosinase activity in horseradish (Armoracia rusticana). Journal of Agricultural and Food Chemistry 52, 69506955.

Malka, O., Shekhov, A., Reichelt, M., Gershenzon, J., Vassão, D.G., and Morin, S. (2016). Glucosinolate desulfation by the phloem-feeding insect Bemisia tabci. Journal of Chemical Ecology, 1-6.

Marcinkowska, M., and Jelen, H.H. (2020). Inactivation of thioglucosidase from Sinapis alba (White Mustard) seed by metal salts. Molecules 25, 13.

Morant, A.V., Jørgensen, K., Jørgensen, C., Paquette, S.M., Sánchez-Pérez, R., Møller, B.L., and Bak, S. (2008). $\beta$-Glucosidases as detonators of plant chemical defense. Phytochemistry 69, 1795-1813.

O'leary, N.A., Wright, M.W., Brister, J.R., Ciufo, S., Haddad, D., Mcveigh, R., Rajput, B., Robbertse, B., Smith-White, B., Ako-Adjei, D., Astashyn, A., Badretdin, A., Bao, Y., 
Blinkova, O., Brover, V., Chetvernin, V., Choi, J., Cox, E., Ermolaeva, O., Farrell, C.M., Goldfarb, T., Gupta, T., Haft, D., Hatcher, E., Hlavina, W., Joardar, V.S., Kodali, V.K., Li, W., Maglott, D., Masterson, P., Mcgarvey, K.M., Murphy, M.R., O'neill, K., Pujar, S., Rangwala, S.H., Rausch, D., Riddick, L.D., Schoch, C., Shkeda, A., Storz, S.S., Sun, H., Thibaud-Nissen, F., Tolstoy, I., Tully, R.E., Vatsan, A.R., Wallin, C., Webb, D., Wu, W., Landrum, M.J., Kimchi, A., Tatusova, T., Dicuccio, M., Kitts, P., Murphy, T.D., and Pruitt, K.D. (2016). Reference sequence (RefSeq) database at NCBI: current status, taxonomic expansion, and functional annotation. Nucleic acids research 44, D733-D745.

Opitz, S.E.W., and Müller, C. (2009). Plant chemistry and insect sequestration. Chemoecology 19, 117-154.

Pentzold, S., Zagrobelny, M., Roelsgaard, P.S., Møller, B.L., and Bak, S. (2014a). The multiple strategies of an insect herbivore to overcome plant cyanogenic glucoside defence. Plos One 9.

Pentzold, S., Zagrobelny, M., Rook, F., and Bak, S. (2014b). How insects overcome twocomponent plant chemical defence: plant $\beta$-glucosidases as the main target for herbivore adaptation. Biological Reviews 89, 531-551.

Prieto, G., Aloria, K., Osinalde, N., Fullaondo, A., Arizmendi, J.M., and Matthiesen, R. (2012). PAnalyzer: a software tool for protein inference in shotgun proteomics. BMC bioinformatics 13, 288-288.

Robert, C.a.M., Zhang, X., Machado, R.a.R., Schirmer, S., Lori, M., Mateo, P., Erb, M., and Gershenzon, J. (2017). Sequestration and activation of plant toxins protect the western corn rootworm from enemies at multiple trophic levels. eLife 6, e29307.

Schindelin, J., Arganda-Carreras, I., Frise, E., Kaynig, V., Longair, M., Pietzsch, T., Preibisch, S., Rueden, C., Saalfeld, S., Schmid, B., Tinevez, J.Y., White, D.J., Hartenstein, V., Eliceiri, K., Tomancak, P., and Cardona, A. (2012). Fiji: an open-source platform for biologicalimage analysis. Nat Methods 9, 676-682.

Schramm, K., Vassao, D.G., Reichelt, M., Gershenzon, J., and Wittstock, U. (2012). Metabolism of glucosinolate-derived isothiocyanates to glutathione conjugates in generalist Lepidopteran herbivores. Insect Biochem Mol Biol 42, 174-182.

Shevchenko, A., Tomas, H., Havlis, J., Olsen, J.V., and Mann, M. (2006). In-gel digestion for mass spectrometric characterization of proteins and proteomes. Nature Protocols 1, 28562860.

Shikita, M., Fahey, J.W., Golden, T.R., Holtzclaw, W.D., and Talalay, P. (1999). An unusual case of 'uncompetitive activation' by ascorbic acid: purification and kinetic properties of a myrosinase from Raphanus sativus seedlings. Biochem J 341, 725-732.

Shukla, S.P., and Beran, F. (2020). Gut microbiota degrades toxic isothiocyanates in a flea beetle pest. Molecular Ecology 29, 4692-4705.

Siemens, D.H., and Mitchell-Olds, T. (1996). Glucosinolates and herbivory by specialists (Coleoptera: Chrysomelidae, Lepidoptera: Plutellidae): Consequences of concentration and induced resistance. Environmental Entomology 25, 1344-1353. 
Sønderby, I.E., Hansen, B.G., Bjarnholt, N., Ticconi, C., Halkier, B.A., and Kliebenstein, D.J. (2007). A systems biology approach identifies a R2R3 MYB gene subfamily with distinct and overlapping functions in regulation of aliphatic glucosinolates. PLoS One 2, e1322.

Sporer, T., Körnig, J., and Beran, F. (2020). Ontogenetic differences in the chemical defence of flea beetles influence their predation risk. Functional Ecology 34, 1370- 1379.

Sun, R., Jiang, X., Reichelt, M., Gershenzon, J., Pandit, S.S., and Vassão, D.G. (2019). Tritrophic metabolism of plant chemical defenses and its effects on herbivore and predator performance. Ecology.

Van Den Bosch, T.J.M., and Welte, C.U. (2017). Detoxifying symbionts in agriculturally important pest insects. Microbial biotechnology 10, 531-540.

Van Geem, M., Harvey, J.A., and Gols, R. (2014). Development of a generalist predator, Podisus maculiventris, on glucosinolate sequestering and nonsequestering prey. Naturwissenschaften 101, 707-714.

Vassão, D.G., Wielsch, N., Gomes, A.M.D.M.M., Gebauer-Jung, S., Hupfer, Y., Svatoš, A., and Gershenzon, J. (2018). Plant Defensive $\beta$-Glucosidases Resist Digestion and Sustain Activity in the Gut of a Lepidopteran Herbivore. Frontiers in Plant Science 9.

Wittstock, U., Agerbirk, N., Stauber, E.J., Olsen, C.E., Hippler, M., Mitchell-Olds, T., Gershenzon, J., and Vogel, H. (2004). Successful herbivore attack due to metabolic diversion of a plant chemical defense. Proc Natl Acad Sci U S A 101, 4859-4864.

Yang, Z.-L., Kunert, G., Sporer, T., Körnig, J., and Beran, F. (2020). Glucosinolate abundance and composition in Brassicaceae influence sequestration in a specialist flea beetle. Journal of Chemical Ecology 46, 186-197.

Zhou, C., Tokuhisa, J.G., Bevan, D.R., and Esen, A. (2012). Properties of $\beta$-thioglucoside hydrolases (TGG1 and TGG2) from leaves of Arabidopsis thaliana. Plant Science 191192, 82-92. 
659 Figures

A

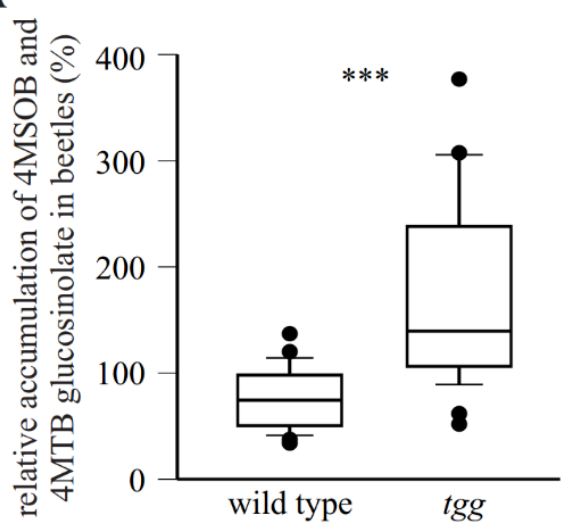

B

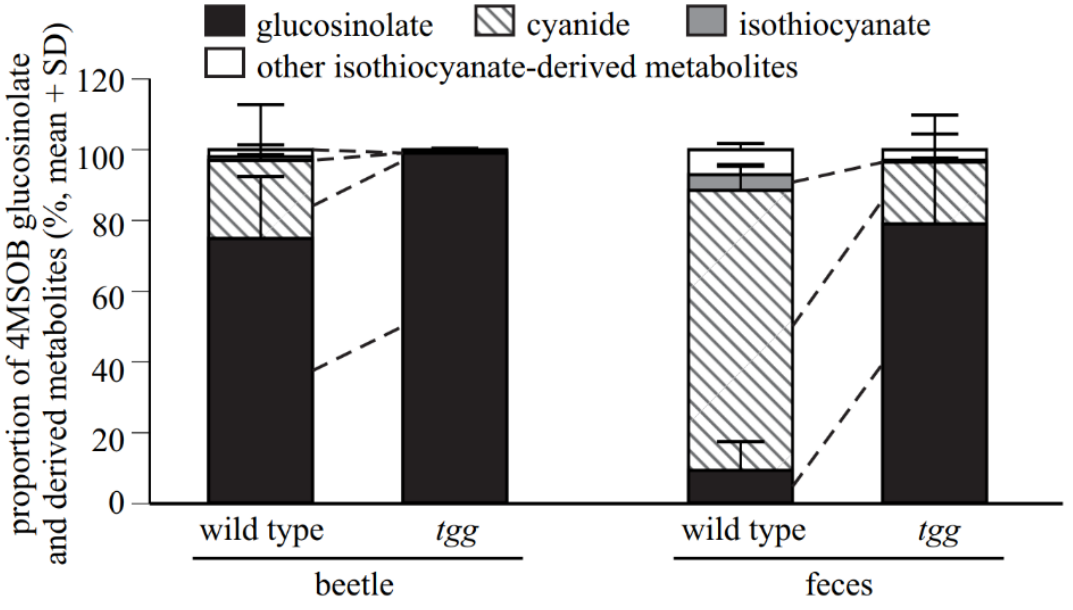

661 Figure 1: Plant myrosinase activity negatively influences the sequestration of 4MSOB 662 glucosinolate in P. armoraciae. (A) Accumulation of 4-methylsulfinylbutyl (4MSOB) and 4663 methylthiobutyl (4MTB) glucosinolate in $P$. armoraciae adults relative to the concentration in fed 664 Arabidopsis wild type and myrosinase-deficient tgg leaves $(\mathrm{n}=28)$. Glucosinolates were quantified after conversion to desulfo-glucosinolates by HPLC-DAD. The glucosinolate concentration in the plant was set to $100 \%$. *** $p<0.001$. (B) Relative composition of 4MSOB glucosinolate and hydrolysis products in bodies and feces of wild type- or $t g g$-fed adults $(\mathrm{n}=5)$. Glucosinolates and hydrolysis products were extracted with $50 \%$ methanol and analyzed by LCMS/MS. Detected amounts of metabolites were expressed relative to the total amounts of all detected metabolites in beetles or feces (set to 100\%). Dashed lines indicate significant differences between samples $(p<0.05)$. Statistical results are shown in Supplementary Table 1. 4MSOB cyanide corresponds to the nitrile hydrolysis product of 4MSOB glucosinolate. Other isothiocyanate-derived metabolites comprise 4MSOB isothiocyanate-glutathione conjugate, 4MSOB isothiocyanate-cysteinylglycine conjugate, 4MSOB isothiocyanate-cysteine conjugate, 2(4-(methylsulfinyl)butylamino)-4,5dihydrothiazole-carboxylic acid, 4MSOB amine, and 4MSOB

676 acetamide. 


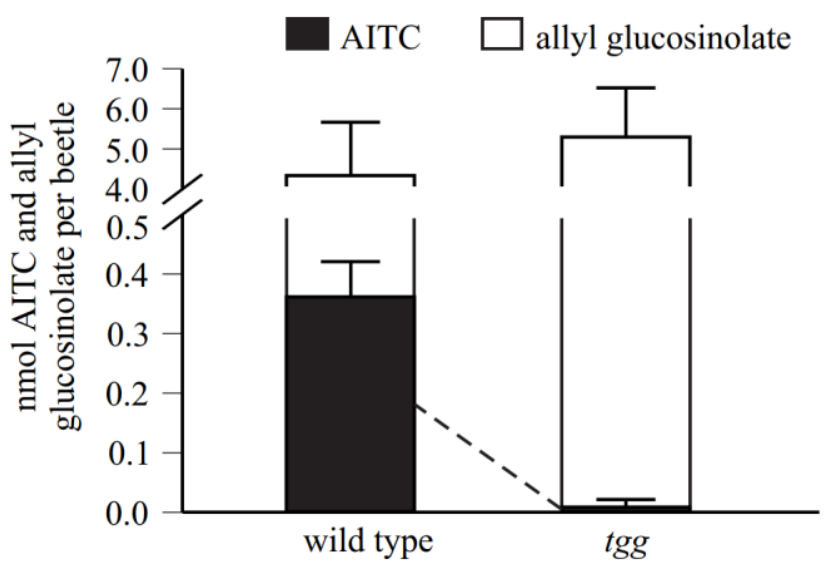

678 Figure 2: Allyl glucosinolate is hydrolyzed during P. armoraciae feeding on Arabidopsis wild type leaves. Adult beetles were fed with allyl glucosinolate-spiked Arabidopsis leaves with (wild 680 type) and without (tgg) myrosinase activity for one day. Headspace volatiles were collected on 681 Porapaq- $\mathrm{Q}^{\mathrm{TM}}$ adsorbent, eluted with hexane, and allyl isothiocyanate was quantified using gas 682 chromatography-mass spectrometry $(\mathrm{m} / \mathrm{z}$ 99). Detected amounts of allyl isothiocyanate were corrected by subtracting the background emission detected in volatile collections performed without beetles, which served as control. Allyl glucosinolate was quantified after conversion to desulfo-glucosinolates by HPLC-DAD. The dashed line indicates significant differences between samples $(p<0.001 ; \mathrm{n}=6-7)$. Results of statistical analyses are provided in Supplementary Table 1. 

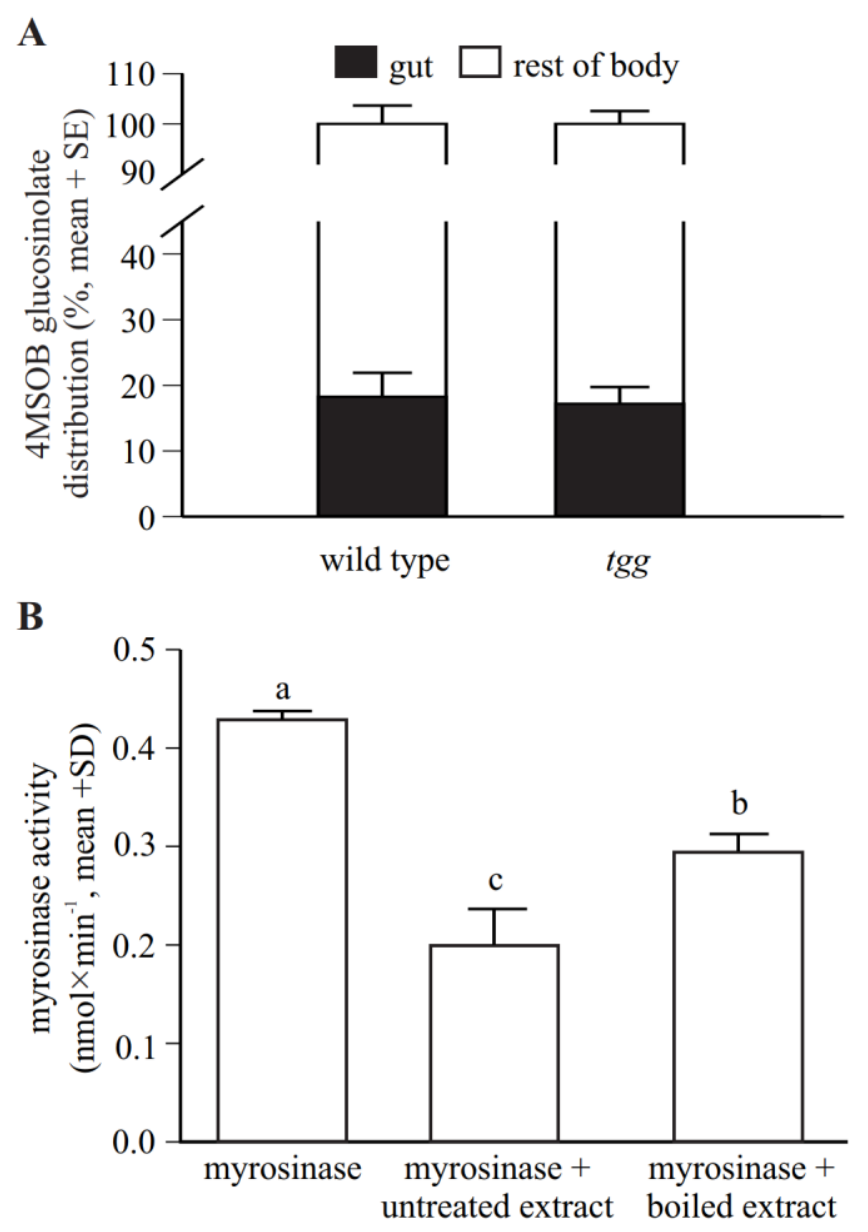

Figure 3: $P$. armoraciae rapidly sequesters ingested glucosinolates and can suppress plant myrosinase activity. (A) Beetles were allowed to feed for 1 min on Arabidopsis leaves with (wild type) or without (tgg) myrosinase activity and were dissected into gut and rest of body 5 min later $(\mathrm{n}=3)$. Beetles were extracted with $80 \%$ methanol and 4MSOB glucosinolate was quantified by LC-MS/MS. The distribution of 4MSOB glucosinolate in gut and rest of body is expressed relative to the total amount detected in both samples (set to 100\%). (B) Partially purified Sinapis alba myrosinase was affected by the supplementation of untreated and boiled gut content extracts in in vitro assays $(n=4)$. Myrosinase activity was determined by quantifying the 4MSOB glucosinolate substrate in each assay after conversion to desulfo-glucosinolate and analysis by HPLC-DAD. Assays without myrosinase served as background controls and activities were subtracted from the corresponding samples. Different letters indicate significant differences, $p<0.001$. 
A

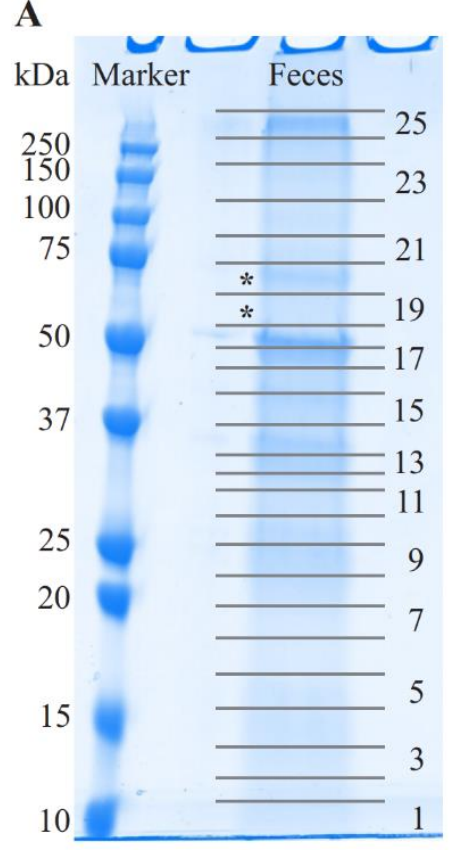

B

TGG1

TGG2

TGG1

TGG2

TGG1

TGG2

TGG1

TGG2

TGG1

TGG2

TGG1

TGG2

TGG1

TGG2

TGG1

TGG2

TGG1

TGG2

TGG1

TGG2
-----------MKLLMLAAFVFLLALATCK-GDEFVCEENEPFTCNQTKLFNSGNFEKGFI

MQHNTYIYILT . . . GF. LAI . .VV . . . PEE. IT . . .V. . . . . . . DR . KQD . .SD . .

FGVASSAYQVEGGRGRGLNYWDSFTHRFPEKGGADLGNGDTTCDSYTLWQKDIDVMDELN

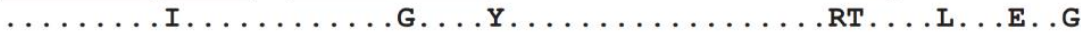

STGYRESIAWSRLLPKGKRSRGVNPGAIKYYNGLIDGLVAKNMTPFVTLFHWDLPQTLQD

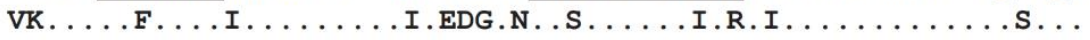

EYNGFLNKTIVDDFKDYADLCFELFGDRVKNWITINOLYTVPTRGYALGTDAPGRCSPKI

. E . . DR . I . . . . . . . R . . . H . . . F . . . . . . . . QWV DVRCPGGNSSTEPYIVAHNQLLAHAAAVDVYRTKYKDDQKGMIGPVMITRWFLPFDHSOE

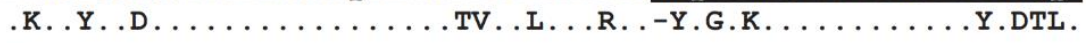

SKDATERAKIFFHGWFMGPLTEGKYPDIMREYVGDRLPEFSETEAAALVKGSYDFLGLNYY

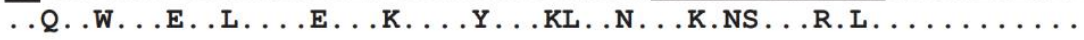
VTQYAQNNQTIVPSDVHTALMDSRTTLTSKNATGHAPGPPFNAASYYYPKGIYYVMDYFK .... HALDP-S. PEKL . MT . . LAN . . ID . N. QP . . . . SKG . . . H. R.MLN . .EH . . TTYGDPLIYVTENGESTPGDE-DFEKATADYKRIDYLCSHLCFLSKVIKEKNVNVKGYFA

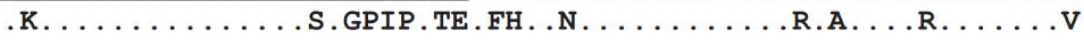
WSLGDNYEFCNGFTVRFGLSYVDFANITGDRDLKASGKWFQKFINVTDEDSTNQDLLRSS $\ldots \ldots \ldots \ldots$. . . . . . . . . V.A. ........Y.S.LR---DTTK...I... VSSKNRDRKSLADA

LPF. .G....T--

703 Figure 4: Detection of ingested Arabidopsis myrosinase in the feces of P. armoraciae. (A) One dimensional SDS/PAGE gel of crude feces protein extract. Numbers indicate samples excised for proteomic analysis by nano-UPLC-MS ${ }^{E}$ (only odd numbers are shown). TGG1-derived peptides were detected in bands marked with asterisks. (B) Amino acid sequence alignment of the Arabidopsis myrosinases TGG1 (AT5G26000.1) and TGG2 (AT5G25980.2). Identical amino acids in the TGG2-sequence are represented by a dot. Peptides highlighted with black background 


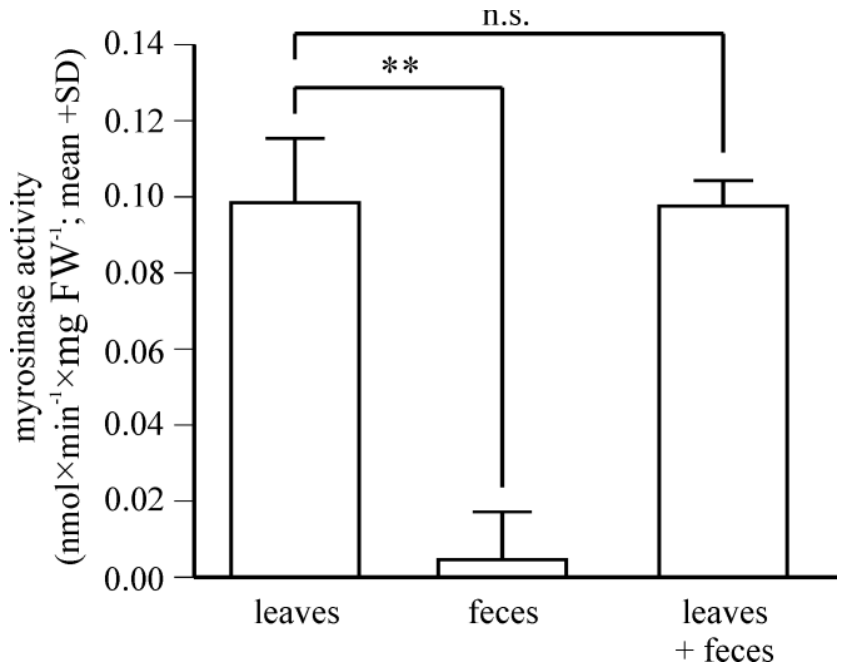

711 Figure 5: Arabidopsis myrosinase activity is strongly reduced after digestion. Enzymatic levels of 712 myrosinase activity in Arabidopsis myb leaves were determined in non-ingested leaf material 713 (leaves) and after beetle digestion (feces) of equivalent amounts. Samples were spiked with 714 4MSOB glucosinolate and the reaction was stopped by heat inactivation after 30 min. Remaining 715 glucosinolate substrate was quantified by LC-MS/MS analysis. Co-incubation of non-ingested 716 myrosinases with $P$. armoraciae feces homogenate did not affect myrosinase activity levels. **, $p$ $717<0.005 ; \mathrm{n} . \mathrm{s} ., p<0.05 ; \mathrm{n}=6$. Statistical results are shown in Supplementary Table 1. 


\section{Tables}

719 Table 1: Recovery of ingested allyl glucosinolate in P. armoraciae.

\begin{tabular}{|c|c|c|c|c|}
\hline & \multicolumn{2}{|c|}{ Mean percentage \pm SD $(n=10)$} & \multirow{2}{*}{$t$} & \multirow{2}{*}{$p$} \\
\hline & wild type-fed & $\operatorname{tg} g$-fed & & \\
\hline Beetle & $43.8 \pm 8.2$ & $53.0 \pm 4.8$ & 2.924 & 0.009 \\
\hline Feces & $0.2 \pm 0.3$ & $0.3 \pm 0.1$ & 0.655 & 0.521 \\
\hline Unknown $^{1}$ & $56.0 \pm 8.4$ & $46.7 \pm 4.8$ & 2.883 & 0.010 \\
\hline
\end{tabular}

$720{ }^{1}$ unrecovered proportion of ingested allyl glucosinolate 